REVIEW

\title{
The utility of the microvascular anastomotic coupler in free tissue transfer
}

\author{
Amandeep S Grewal MD ${ }^{1}$, Boban Erovic MD¹, Nick Strumas MD, FRCSC ${ }^{2}$, \\ Danny J Enepekides MD FRCSC ${ }^{1}$, Kevin M Higgins MD MSc FRCSC ${ }^{1}$
}

\begin{abstract}
AS Grewal, B Erovic, N Strumas, DJ Enepekides, KM Higgins. The utility of the microvascular anastomotic coupler in free-tissue transfer. Can J Plast Surg 2012;20(2):98-102.
\end{abstract}

BACKGROUND: The microvascular anastomosis remains a technically sensitive and critical determinant of success in free tissue transfer. The microvascular anastomotic coupling device is an elegant, friction-fit ring pin device that is becoming more widely used.

OBJECTIVE: To systematically review the literature to examine the utility of the microvascular coupler in free tissue transfer.

METHODS: A comprehensive database search was performed to identify eligible publications. Inclusion criteria were anastomotic coupler utilization and free-tissue transfer. Recorded information from eligible studies included patient age, follow-up, radiation history, number of free-flaps and failure rates, reconstruction subsites, number of coupled venous and arterial anastomoses, coupling time, conversion to sutured anastomosis, coupler size and thrombosis rates.

RESULTS: Twenty-five studies reporting on 3207 patients were included in the analysis. A total of 3576 free-flaps were performed within the following subsites: 1103 head and neck, 2094 breast, 300 limb or body, and 79 nonspecified. There were only 26 reported flap failures $(0.7 \%)$. A total of 3497 venous and 342 arterial coupled anastomoses were performed. The primary outcome measure was thrombosis rates, and there were 61 venous (1.7\%) and 12 arterial (3.6\%) thromboses reported. Mean coupling time was $5 \mathrm{~min}$, and 30 anastomoses $(0.8 \%)$ were converted to suture.

CONCLUSION: Flap survival and revision-free application of the microvascular coupler occurred in more than $99 \%$ of cases. There is a substantial time savings with coupler use. Venous and arterial thrombosis rates are comparable with the best results achieved by sutured anastomosis and, when used by experienced surgeons, the coupler achieves superior results.

Key Words: Free tissue transfer; Microvascular anastomosis; Ring pin; Venous coupler

$\mathrm{T}$ he transfer of autogenous, vascularized free-tissue is a cornerstone of modern reconstructive surgery, particularly when dealing with extensive oncological ablations and large post-traumatic defects. A half-century after Jacobson and Suarez (1) described the first sutured microvascular anastomosis, the cumulative efforts of surgeons and researchers have refined free tissue transfer (FTT) into a reliable modality that often provides excellent cosmetic and functional results.

In addition to adequate presurgical planning and meticulous dissection technique, the microvascular anastomosis is critically important for successful reconstruction. The reported success rate of FTT ranges from $91 \%$ to $99 \%$, with the majority of failures being due to technical errors with vessel anastomosis (2). Indeed, a hand-sewn anastomosis is a technically demanding procedure, particularly when dealing with veins, which prompted investigation into alternative strategies to suture. One example is the microvascular anastomotic coupling device (MACD), an interlocking ring-pin design that is

\section{L'utilité du coupleur d'anastomose, en cas de transfert de tissu libre}

HISTORIQUE : L'anastomose microvasculaire demeure un déterminant délicat et essentiel de la réussite du transfert de tissu libre. Le coupleur d'anastomose miscrovasculaire est un élégant anneau broché adapté à la friction qui est de plus en plus utilisé.

OBJECTIF : Procéder à une analyse bibliographique systématique pour évaluer l'utilité du coupleur microvasculaire en cas de transfert de tissu libre.

MÉTHODOLOGIE : Les chercheurs ont effectué une recherche approfondie dans les bases de données pour repérer les publications admissibles. Les critères d'inclusion étaient l'utilisation d'un coupleur anastomotique et le transfert de tissus libre. L'information consignée à partir des études admissibles était l'âge du patient, le suivi, les antécédents de radiation, le nombre de lambeaux libres et le taux d'échecs, les sous-foyers de reconstruction, le nombre de couplages anastomotiques veineux et artériels, la durée du couplage, la conversion en anastomose suturée, la dimension du coupleur et le taux de thromboses.

RÉSULTATS : Les chercheurs ont inclus 25 études portant sur 3207 patients dans l'analyse. Au total, 3576 transferts de lambeaux libres ont été effectués, dans les sous-foyers suivants : 1103 sur la tête et le cou, 2094 sur le sein, 300 sur un membre ou le corps et 79 à un foyer non précisé. Seulement 26 échecs du lambeau (0,7 \%) étaient déclarés. Au total, 3497 anastomoses veineuses couplées et 342 anastomoses artérielles couplées ont été exécutées.La mesure d'issue primaire était le taux de thrombose; 61 thromboses veineuses $(1,7 \%)$ et 12 thromboses artérielles $(3,6 \%)$ ont été déclarées. Le couplage durait en moyenne cinq minutes, et 30 anastomoses $(0,8 \%)$ ont été converties en suture.

CONCLUSION : On observe la survie du lambeau et l'application sans révision du coupleur microvasculaire dans plus de $99 \%$ des cas. On gagne beaucoup de temps à utiliser le coupleur. Le taux de thromboses veineuses et artérielles est similaire, et les meilleurs résultats proviennent des anastomoses suturées. Lorsqu'il est utilisé par des chirurgiens expérimentés, le coupleur donnait des résultats supérieurs.

becoming more widely used in FTT. Initial animal studies demonstrated favourable tensile characteristics and healing of coupled vessels (3), and subsequent case series in head and neck, breast and limb reconstructive surgery have reported favourably on MACD utilization. These case series have been limited by smaller numbers and variability in reconstructive subsites; however, recently, several larger series have been published. We sought to systematically review the literature to examine the utility of MACD use in FTT with regard to success rates and optimal applications of this device.

\section{METHODS}

A search of PubMed, Ovid MEDLINE, and EMBASE databases (inception to January 2011) was performed using major search terms including "microvascular anastomotic coupler", "anastomotic device", "venous coupler", "Nakayama ring pin" and "free tissue transfer". Two independent reviewers performed the title and abstract review, identifying relevant articles for retrieval. Inclusion criteria were MACD utilization and FTT reconstruction. There was no limitation placed on

\footnotetext{
${ }^{1}$ University of Toronto, Sunnybrook Health Sciences Centre, Department of Otolaryngology, Head and Neck Surgery, Toronto;

${ }^{2}$ McMaster University, McMaster University Medical Centre, Division of Plastic and Craniomaxillofacial Surgery, Hamilton, Ontario

Correspondence: Dr Kevin Higgins, Sunnybrook Health Sciences Centre, Department of Otolaryngology, Head and Neck Surgery,

2075 Bayview Avenue, Suite M1 102, Toronto, Ontario M4N 1J7. Telephone 416-480-5104, fax 416-480-5761,

e-mail kevin.higgins@sunnybrook.ca
} 
study design, and articles not published in English and animal studies were excluded. Study references were examined to ensure inclusion of all relevant publications. Any disagreement on study eligibility between reviewers was resolved by group consensus. Inclusion agreement between reviewers was excellent, with the kappa calculated to be 89\% (Figure 1).

A data abstraction tool was designed and applied to all eligible studies. Recorded information included the number and age of patients, follow-up, radiation history, number of FTT and failure rates, reconstruction subsites, number of coupled venous and arterial anastomoses, coupling time, conversion to sutured anastomosis, coupler size used and thrombosis rates. Two indepenedent reviewers performed data abstraction on all included studies with consensus resolution of any discrepencies.

\section{RESULTS}

The initial database search generated 425 results, and subsequent title and abstract screening by two independent reviewers identified 31 studies for full-text review and potential inclusion. Following full-text review and consensus, 25 studies were included for analysis using the data abstraction tool (4-28). Reasons for exclusion are listed in Figure 1 (29-34). Overall, one included study was prospective (15) and the remaining 24 were retrospective in design.

A total of 3207 patients with a mean age of 49.8 years were enrolled in the included studies, not considering series that presented age ranges only (Table 1 ). Mean follow-up data were only provided in nine of 25 studies (14.4 months), although other authors provided a range (data not shown). A total of 3576 FTTs were performed in these patients within the following subsites: 1103 head and neck, 2094 breast, 300 limb or body, and 79 nonspecified (Figure 2). The status of preoperative radiotherapy was reported in only six studies, comprising 128 FTTs (data not shown). There were only 26 reported flap failures $(0.7 \%)$.

Regarding MACD use, a total of 3497 venous and 342 arterial coupled anastomoses were performed in these patients (Table 1). The primary outcome measure was thrombosis rates and, from the pooled data, there were 61 venous $(1.7 \%)$ and 12 arterial $(3.6 \%)$ thromboses reported. Time for completion of a coupled anastomosis was recorded in 14 of 25 studies, with a mean of $5.02 \mathrm{~min}$. There were 30 revision anastomoses $(0.8 \%)$ that were converted intra- or postoperatively to sutured anastomoses (data not shown).

MACD size data were summarized and a comparison was made between the rates of thrombosis and coupler size (Table 2). For venous anastomoses, coupler size was reported by authors in 2094 of 3503 cases (59.8\%), with the majority of veins coupled using the $3 \mathrm{~mm}$ and $2.5 \mathrm{~mm}$ ring pins. When stratified according to size, the anastomotic failure rates ranged from $0.3 \%$ to $0.8 \%$; however, for the majority of complications the coupler size was not reported.

For arterial anastomosis, the coupler size used was reported in 243 of 340 cases $(71.5 \%)$. The smallest size used was $1.5 \mathrm{~mm}$, and there were two reported thromboses $(8.0 \%)$. The thrombosis rates were $6.5 \%$ for the $2.0 \mathrm{~mm}$ coupler, $4.2 \%$ for the $2.5 \mathrm{~mm}$ coupler and $1.7 \%$ for the $3 \mathrm{~mm}$ coupler.

\section{DISCUSSION}

After introduction of the MACD in the 1980s, preliminary histological and animal studies supported its use as an advantageous alternative to hand-sewn microvascular anastomoses (3). In subsequent years, more surgeons have been using the MACD in FTT, and there has been a steady accumulation of case series in the literature that report favourably on its performance. However, patient numbers have generally been low, and a variety of research questions have been targeted: use in veins compared with arteries; in radiated patients; in vessel diameter mismatch; and across different subsites, are some examples. With the recent publication of several large case series, there are finally adequate numbers to allow for a more accurate utility analysis of this elegant technology.

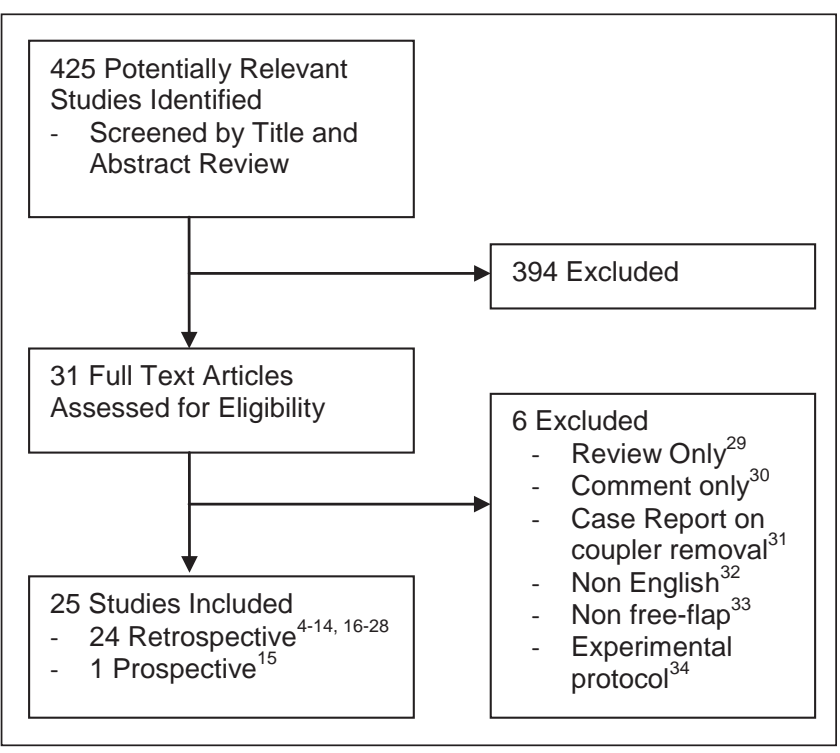

Figure 1) Identification of relevant publications

Widely cited advantages of the MACD include intima-to-intima anastomosis and reliable vessel eversion, thereby avoiding a potentially thrombogenic foreign body within the vessel lumen. The anastomotic site is rigidly stented open by the external MACD rings, which protects against vessel collapse or spasm, especially true of venous anastomoses, and the everted vessel edges can be more easily inspected to ensure no misadventure during coupling when compared with sutured anastomosis. Potential challenges with MACD use include possible helical twisting of the vessel during coupling and possible intimal trauma during vessel eversion (26).

Published flap survival rates in FTT generally range from 91\% to $99 \%$ (2). In the present review, there were only 26 reported flap failures for 3576 FTTs performed, equating to a $99.3 \%$ success rate. Also notable, there were only 30 reported cases of suture conversion after unsuccessful coupling, implying that the MACD performs successful anastomosis in more than $99 \%$ of attempted cases.

The principle outcome measure for evaluating MACD use is thrombosis, a primary cause of FTT failure. In the present pooled analysis of all previously published series on MACD use in FTT, there were only 61 venous thromboses from 3493 coupled anastomoses (1.7\%), and 12 arterial thromboses from 337 anastomoses (3.7\%). The difference in thrombosis versus flap failure rates is accounted for by the successful salvage of most thrombosed free flaps.

A direct comparison between sutured versus coupled anastomosis is challenging due to considerable variability of results across the literature; however, there are examples of both modalities being used by the same institutions. One example is the University of Pennsylvania (Philadelphia, USA) experience, from which several interesting conclusions can be drawn. Their recently published MACD series reports on 1000 consecutive FTT breast reconstructions with coupled venous anastomosis (16), in which they observed only six instances of venous thrombosis $(0.6 \%)$ and zero flap failures. These success rates are outstanding, representing the best results within the present review. Comparatively, this group also published their series on 569 consecutive free transverse rectus abdominis myocutaneous flaps, which were all anastomosed using 9-0 nylon, in which they experienced one total flap loss $(0.2 \%), 16$ venous thromboses $(2.8 \%)$, and 19 arterial thromboses (3.3\%) (35). At publication, this series had represented the highest flap survival and lowest thrombosis rates of a large FTT cohort to date. However, after switching to the MACD, they were able to actually lower their venous thrombosis rates from $2.8 \%$ to $0.6 \%$, and achieve $100 \%$ flap survival. In addition, it is impressive to consider that the pooled flap survival, venous thrombosis and arterial thrombosis rates in 
TABLE 1

Data from coupler studies

\begin{tabular}{|c|c|c|c|c|c|c|c|c|c|c|c|c|c|}
\hline \multirow{2}{*}{$\begin{array}{l}\text { First author } \\
\text { (reference), year }\end{array}$} & \multirow[b]{2}{*}{ Patients } & \multirow{2}{*}{$\begin{array}{l}\text { Age, } \\
\text { years }\end{array}$} & \multirow[b]{2}{*}{ FTT } & \multirow[b]{2}{*}{ Failures } & \multicolumn{4}{|c|}{ Reconstruction subsites } & \multicolumn{2}{|c|}{ Anastamosis } & \multicolumn{2}{|c|}{ Thrombosis } & \multirow{2}{*}{$\begin{array}{c}\text { Coupling } \\
\text { time, } \\
\text { min }\end{array}$} \\
\hline & & & & & $\mathrm{HN}$ & Breast & Body & Unspec & Venous & Arterial & Venous & Arterial & \\
\hline Jandali (16), 2010 & 730 & - & 1000 & 2 & 0 & 1000 & 0 & 0 & 1000 & 0 & 6 & 0 & 3 \\
\hline Camara (6), 2009 & 11 & 50.1 & 11 & 0 & 0 & 11 & 0 & 0 & 11 & 1 & 0 & 0 & - \\
\hline Chernichenko (8), 2008 & 124 & 66 & 127 & 3 & 127 & 0 & 0 & 0 & 0 & 124 & 0 & 4 & - \\
\hline Chang (7), 2007 & 25 & 41 & 25 & 0 & 11 & 0 & 14 & 0 & 30 & 0 & 0 & 0 & 6.3 \\
\hline Knight (17), 2006 & 79 & 48 & 101 & 1 & 0 & 101 & 0 & 0 & 96 & 0 & 2 & 0 & - \\
\hline Spector (24), 2006 & 46 & 45.9 & 62 & 0 & 0 & 62 & 0 & 0 & 0 & 62 & 0 & 1 & 5 \\
\hline Ross (20), 2005 & 49 & 64 & 50 & 0 & 50 & 0 & 0 & 0 & 100 & 0 & 2 & 0 & - \\
\hline Sullivan (25), 2003 & 38 & - & 38 & 0 & 0 & 38 & 0 & 0 & 49 & 0 & 0 & 0 & 3.5 \\
\hline Nishimoto (18), 2000 & 89 & - & 98 & 0 & 98 & 0 & 0 & 0 & 121 & 0 & 0 & 0 & - \\
\hline Denk (14), 1995 & 11 & 35 & 11 & 0 & 0 & 0 & 11 & 0 & 14 & 0 & 0 & 0 & 8 \\
\hline Ahn (4), 1994 & 74 & 44 & 100 & 0 & 12 & 79 & 9 & 0 & 103 & 29 & 2 & 0 & 4 \\
\hline Sasson (22), 1994 & 9 & 49 & 10 & 0 & 2 & 0 & 8 & 0 & 10 & 0 & 0 & 0 & 5 \\
\hline Rozen (21), 2010 & 1000 & - & 1000 & 0 & 250 & 600 & 150 & 0 & 930 & 70 & 29 & 0 & 4 \\
\hline Chernichenko (9), 2008 & 96 & 65 & 96 & 1 & 96 & 0 & 0 & 0 & 173 & 0 & 4 & 0 & - \\
\hline Hallock (15), 2008 & 38 & - & 38 & 0 & 0 & 0 & 0 & 38 & 55 & 0 & 0 & 0 & - \\
\hline Yap (26), 2006 & 139 & - & 139 & 1 & 81 & 53 & 5 & 0 & 139 & 0 & 2 & 0 & - \\
\hline Rosenthal (19), 2004 & 117 & 62 & 125 & 3 & 125 & 0 & 0 & 0 & 125 & 0 & 1 & 0 & - \\
\hline Zeebregts (27), 2002 & 200 & 54 & 216 & 10 & 93 & 59 & 64 & 0 & 159 & 1 & 7 & 0 & 9 \\
\hline Cope (10), 2001 & 82 & 47.7 & 100 & 0 & 8 & 91 & 0 & 1 & 100 & 4 & 1 & 0 & 5 \\
\hline DeLacure (12), 1999 & 27 & 53 & 27 & 0 & 27 & 0 & 0 & 0 & 33 & 0 & 0 & 0 & 5 \\
\hline Shindo (23), 1996 & 76 & - & 79 & 1 & 79 & 0 & 0 & 0 & 88 & 17 & 0 & 2 & 5.5 \\
\hline De Bruijn (11), 1996 & 72 & 44 & 54 & 2 & 15 & 0 & 39 & 0 & 85 & 2 & 2 & 2 & 4 \\
\hline DeLacure (13),1995 & 29 & 49 & 29 & 0 & 29 & 0 & 0 & 0 & 30 & 7 & 1 & 0 & - \\
\hline Berggren (5), 1993 & 26 & 54 & 20 & 0 & - & - & - & 20 & 21 & 5 & 0 & 1 & 3 \\
\hline Zhou (28), 1989 & 20 & 25.1 & 20 & 2 & - & - & - & 20 & 25 & 20 & 2 & 2 & - \\
\hline Total & 3207 & 49.8 & 3576 & 26 & 1103 & 2094 & 300 & 79 & 3497 & 342 & 61 & 12 & 5.02 \\
\hline
\end{tabular}

Data presented as $n$ unless otherwise indicated. FTT Free tissue transfer; HN Head and neck; Unspec Unspecified subsite

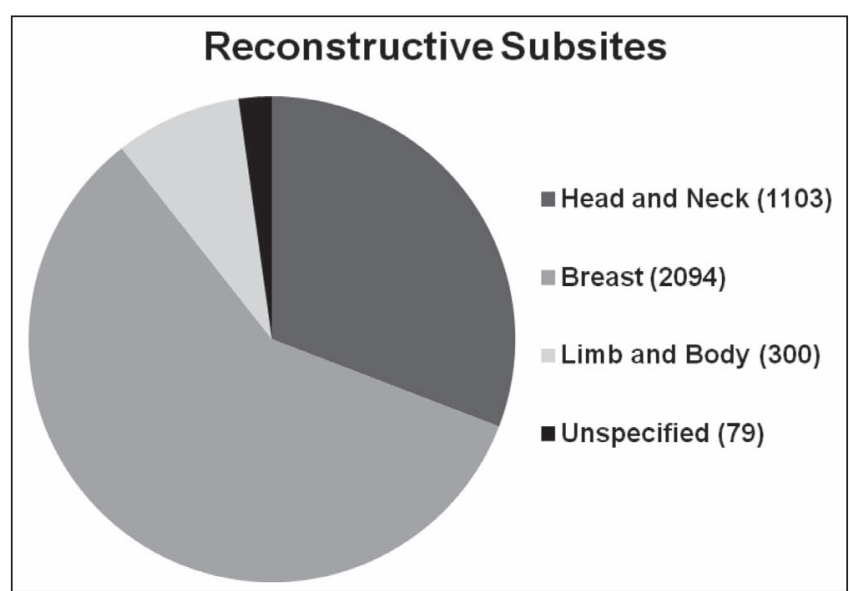

Figure 2) Free flaps according to subsite

this review are highly comparable with the 'optimal' hand-sewn results achieved by Serletti et al (99.3\% versus $99.7 \%, 1.7 \%$ versus $2.8 \%$, and $3.7 \%$ versus $3.3 \%$, respectively). The fact that MACD application by many surgeons across multiple subsites can generate results comparable with sutured anastomosis in a selected group of breast reconstruction patients from a specialized tertiary-care institution is quite promising.

Although the MACD is more established in the anastomosis of veins compared with arteries, there is promising evidence to suggest that arterial coupling may be a reliable alternative to suture anastomosis. As early as 1989, Zhou et al (28) reported on 20 free flaps in which 17 arterial anastomoses were completed with ring pin couplers,
TABLE 2

Anastomosis failure rates according to coupler size

\begin{tabular}{cccc}
\hline Venous coupling according to size & & \\
\hline Size, $\mathbf{m m}$ & Anastomoses, $\mathbf{n}$ & Failures, $\mathbf{n}$ & $\%$ \\
\hline 1 & 0 & 0 & \\
1.5 & 61 & 0 & 0.3 \\
2 & 326 & 1 & 0.6 \\
2.5 & 670 & 4 & 0.8 \\
3 & 1026 & 8 & \\
3.5 & 6 & 0 & \\
4 & 5 & 0 & 3.7 \\
NR & 1409 & 52 &
\end{tabular}

Arterial coupling according to size

\begin{tabular}{cccc}
\hline Size, $\mathbf{m m}$ & Anastomoses, $\mathbf{n}$ & Failures, $\mathbf{n}$ & $\%$ \\
\hline 1 & 0 & 0 & \\
1.5 & 25 & 2 & 8.0 \\
2 & 62 & 4 & 6.5 \\
2.5 & 96 & 4 & 4.2 \\
3 & 60 & 1 & 1.7 \\
3.5 & 0 & 0 & \\
4 & 0 & 0 & \\
NR & 97 & 8 & 8.2
\end{tabular}

NR Not reported

and 15 of these flaps survived. In 1994, Ahn et al (4) reported on 100 FTTs in which 29 arterial anastomoses were attempted with the MACD. Intraoperatively, five cases required conversion to suture for the arterial anastomosis due to thickened vessel walls that caused flow 
obstruction when everted over the ring pins. The remaining 24 arterial anastomoses were comprised of $152.0 \mathrm{~mm}$ rings, $141.5 \mathrm{~mm}$ rings and all were successful. In 1996 Shindo et al (23) reported on 79 head and neck flaps, which included 17 arterial anastomoses with the MACD. In one case, intraoperative thrombosis was noted due to challenging eversion and an intimal tear, which required conversion to suture and, in another case, there was flap loss due to arterial insufficiency.

In 2006, Spector et al (24) reported specifically on the application of the MACD in arterial anastomosis. In 80 consecutive breast flaps, a total of 62 coupled arterial anastomoses were performed. Overall, flap survival was $100 \%$, and in one instance, a revision of the arterial anastomosis was required. Remarkably, the average time to complete the arterial anastomosis was only $5 \mathrm{~min}$. Reasons cited for not using the coupler included significant vessel size mismatch, or nonpliable and thick-walled arteries. The authors comment that becoming proficient with veins is important before attempting arterial coupling. Emphasis is placed on atraumatic vessel handling and minimizing intimal trauma during eversion over the tines of the ring pins. A silicone vessel loop is used to sequentially secure the everted vessel wall down before moving onto the opposing tines to avoid detachment. Criteria to forego the MACD for a sutured arterial anastomosis include greater than 1.5:1 vessel size mismatch, thick walled or nonpliable arteries, or the need for an end-to-side anastomosis.

Chernichenko et al (8) published the largest series of arterial coupling in 124 consecutive head and neck flaps to date. They experienced only four arterial thromboses (3.2\%), of which three were salvageable. Overall flap survival was $97.6 \%$. The authors emphasized that dilating arteries to use at least a $2.5 \mathrm{~mm}$ coupler is essential for successful anastomosis. Arteries were dilated with the tips of a curved micro-needle holder because the spring-action handle provided greater dilating force than the standard vessel dilator used for veins. Some thickwalled arteries appear to exhibit intimal cracking or tearing after eversion onto the ring pins; however, these vessels generally approximated easily with satisfactory bloodflow and low thrombosis rates. The authors hypothesized that intimal trauma is limited to the areas of vessel eversion that eventually become opposed, with no exposure of thrombogenic subendothelial elements to the circulating blood. The authors believe that the majority of arteries can be coupled and that the MACD is actually preferred over suture for arterial anastomosis at their institution, even in radiated patients. Cited reasons for suturing include extensive atherosclerosis, inability to dilate the arteries to use at least a $2.5 \mathrm{~mm}$ coupler or pseudoaneurysm formation.

\section{REFERENCES}

1. Jacobson JI, Suarez EL. Microsurgery in anastomosis of small vessels. Surg Forum. 1960;11:243-45.

2. Gardiner MD, Nanchahal J. Strategies to ensure success of microvascular free tissue transfer. J Plast Recon Aesthetic Surg 2010;63:665-73.

3. Gilbert RW, Ragnarsson R, Berggren A, et al. Strength of microvascular anastomosis: Comparison between the UNILINK anastomotic system and sutures. Microsurgery 1989;10:40-6.

4. Ahn CY, Shaw WW, Berns S, et al. Clinical experience with the $3 \mathrm{M}$ microvascular coupling anastomotic device in 100 free-tissue transfers. Plast Reconstr Surg 1994;93:1481-4.

5. Berggren A, Ostrup LT, Ragnarsson R. Clinical experience with the Unilink/3M Precise microvascular anastomotic device.

Scand J Plas Reconst Surg Hand Surg 1993;27:35-9.

6. Camara O, Herrmann J, Egbe A, et al. Venous coupler for free-flap anastomosis. Anticanc Res 2009;29:2827-30.

7. Chang KP, Lin SD, Lai CS. Clinical experience of a microvascular venous coupler device in free tissue transfers. Kaohsiung J Med Sci 2007:23:566-72.

8. Chernichenko N, Ross DA, Shin J, et al. Arterial coupling for microvascular free tissue transfer. Otol Head Neck Surg 2008;138:614-8.

9. Chernichenko N, Ross DA, Shin J, et al. End-to-side venous anastomosis with an anastomotic coupling device for microvascular
A universally cited advantage of the MACD is time-savings over a sutured anastomosis. Data regarding the average anastomotic time were available for 14 of 25 included studies, comprising approximately 2800 anastomoses. The pooled average time to completion of the anastomosis was an impressive $5.02 \mathrm{~min}$. In contrast, several studies have documented the time to complete a sutured anastomosis at between $22 \mathrm{~min}$ and $25 \mathrm{~min}$, comparable between arteries and veins $(21,27)$. Of course, this four-fold time savings is multiplied when dealing with double-vein flaps or bilateral free-flap reconstructions. Difficult anastomoses in the head and neck can take in excess of $30 \mathrm{~min}$ to complete due to confined surgical fields, such as at the angle of the mandible. The compact nature of the MACD can also help dramatically lower anastomosis times by facilitating access to such challenging areas.

An important question is whether a cost-saving exists when weighing the increased financial cost of using this technology versus the operating room time savings. Although some authors espouse that operating room time savings do offset the device cost, to date, a comprehensive cost-benefit analysis has not been performed.

The retrospective publication of case series is vulnerable to selection and observation bias, and 24 of the 25 published series on MACD use were retrospective in nature. However, this bias also threatens comparable published series on hand-sewn anastomoses. The relatively low event rate of thrombosis or flap failure in FTT, irrespective of anastomotic modality, would make a large prospective cohort study unfeasible.

We have performed the most extensive review of the utility of the microvascular anastomotic coupler in free-flap surgery to date. Impressively, flap survival and revision-free application of the MACD occurs in greater than $99 \%$ of cases. Venous and arterial thrombosis rates are comparable with the best results achieved via sutured anastomosis and, when used by experienced surgeons, the MACD achieves superior results. Well established for venous anastomosis, there appears to be a role for the coupler in arterial anastomosis as well. A successful arterial coupling requires careful consideration of factors such as adequate luminal diameter and coupler size, minimal vessel size mismatch, ease of vessel wall eversion, presence of atherosclerosis and surgeon experience. Another primary advantage of the MACD over conventional suture anastomosis is substantial operative time savings, although a formal cost-benefit analysis has not yet been performed. As experience pertaining to MACD use in FTT has grown, sufficient evidence exists to allow accurate evaluation of its performance. The results are very encouraging.

free-tissue transfer in head and neck reconstruction. Laryngoscope 2008; 118:2146-50

10. Cope C, Ng RL, Miller M, Langstein H. Technique And Clinical Experience Of The Unilink $/ 3 \mathrm{M}^{\circledR}$ Microvascular Anastomotic Coupling Device In Free Flap Surgery. Internet J Plast Surg 2001;1:1.

11. De Bruijn HP, Marck KW. Coupling the venous anastomosis: Safe and simple. Microsurgery 1996;17:414-6.

12. DeLacure MD, Kuriakose A, Spies AL. Clinical experience in endto-side venous anastomosis with a microvascular anastomotic coupling device in head and neck reconstruction. Arch Otolaryngol Head Neck Surg 1999;125:869-72.

13. DeLacure MD, Wong RS, Markowitz BL, et al. Clinical experience with a microvascular anastomotic device in head and neck reconstruction. Am J Surg 1995;170:521-3.

14. Denk MJ, Longaker MT, Basner AL, et al. Microsurgical reconstruction of the lower extremity using the $3 \mathrm{M}$ microvascular coupling device in venous anastomosis. Ann Plast Surg 1995;35:601-6.

15. Hallock GG, Rice DC. Early experience with the new 'megacoupler' ring-pins for microvascular anastomoses. J Plast Reconstr Aesth Surg 2008;61:974-6.

16. Jandali S, Wu LC, Vega SJ, et al. 1000 consecutive venous anastomosis using the microvascular anastomotic coupler in breast reconstruction. Plast Reconst Surg 2010;125:792-8. 
17. Knight MAK, Nguyen DT, Kobayashi MR, et al. Institutional review of free TRAM flap breast reconstruction. Ann Plast Surg 2006;56:593-8.

18. Nishimoto S, Hikasa H, Ichino N, et al. Venous anastomosis with a microvascular anastomotic device in head and neck reconstruction. J Reconstr Microsurg 2000;16:553-6.

19. Rosenthal E, Carroll W, Dobbs M, et al. Simplifying head and neck microvascular reconstruction. Head Neck 2004;26:930-6.

20. Ross DA, Chow JY, Shin J, et al. Arterial coupling for microvascular free tissue transfer in head and neck reconstruction. Arch Otolaryngol Head Neck Surg. 2005;131:891-5.

21. Rozen WM, Whitaker IS, Acosta R. Venous coupler for free-flap anastomosis: Outcomes of 1000 cases. Anticanc Res. 2010;30:1293-4.

22. Sasson HN, Stofman GM, Berman P. Clinical use of the $3 \mathrm{M}$ mechanical microcoupling device in free tissue transfer. Microsurgery 1994;15:421-3.

23. Shindo ML, Costantino PD, Nalbone VP, et al. Use of a mechanical microvascular anastomotic device in head and neck free tissue transfer. Arch Otolaryngol Head Neck Surg 1996;122:529-32.

24. Spector JA, Draper LB, Levine JP, et al. Routine use of microvascular coupling device for arterial anastomosis in breast reconstruction. Ann Plast Surg 2006;56:365-8.

25. Sullivan SK, Dellacroce F, Allen R. Management of significant venous discrepancy with microvascular venous coupler. J Reconstr Microsurg 2003;19:377-80.

26. Yap LH, Constantinides J, Butler CE. Venous thrombosis in coupled versus sutured microvascular anastomosis. Ann Plast Surg 2006;57:666-9.
27. Zeebregts C, Acosta R, Bolander L, et al. Clinical experience with non-penetrating vascular clips in free-flap reconstructions. Br J Plast Surg. 2002;55:105-10.

28. Zhou G, Ling Y, Qiao Q. Experience using microvascular anastomotic rings for the transplantation of 20 free flaps. Plast Reconstr Surg. 1989;84:822-6.

29. Barker EV, Enepekides DJ. The utility of microvascular anastomotic devices in head and neck reconstruction. Curr Opin Otolaryngol Head Neck Surg 2008;16:331-4.

30. Hallock GG. On "Management of significant venous discrepancy with microvascular venous coupler". J Recon Microsurg 2004;20:59.

31. Hilliard S, Pommier R, Solomon JS. Delayed removal of $3 \mathrm{M}$ vein coupler does not disturb the anastomosis. Microsurgery 2009;29:502-3.

32. Cricri G, Afelli F, Caravelli G, et al. Mechanical microanastomosis in reconstructive surgery of the neck and face. Suppl Tumori 2005;4:S182-3.

33. Klima U, Kofidis T, Boening A, et al. Long term angiographic monitoring reveals safety and efficacy of the Converge end-to-side anastomotic coupler. Interact CardioVasc Thorac Surg. 2005;4:505-8.

34. Mohebali J, Gottlieb LJ, Agarwal JP. Further validation for use of the retrograde limb of the internal mammary vein in deep inferior epigastric perforator flap breast reconstruction using laser-assisted indocyanine green angiography. J Recon Microsurg 2010;26:131-6.

35. Vega S, Smartt JM, Jiang S, et al. 500 Consecutive patients with free TRAM flap breast reconstruction: A single surgeon's experience. Plast Reconstr Surg 2008;122:329-39. 